УДК 517.9

\title{
Baroclinic Seiches for Three-Layer Density Stratification in the Basin of Rectangular Shape
}

\author{
Victor M. Belolipetskii \\ Institute of Computational Modelling SB RAS \\ Akademgorodok, 50/44, Krasnoyarsk, 660036 \\ Institute of Mathematics and Computer Science \\ Siberian Federal University \\ Svobodny, 79, Krasnoyarsk, 660041 \\ Russia \\ Svetlana N. Genova* \\ Institute of Computational Modelling SB RAS \\ Akademgorodok, 50/44, Krasnoyarsk, 660036 \\ Russia \\ Andrey G. Degermendzhy ${ }^{\dagger}$ \\ Alexander P. Tolomeyev $\ddagger$ \\ Institute of Biophysics SB RAS \\ Akademgorodok, 50/50, Krasnoyarsk, 660036
}

Russia

Received 25.01.2015, received in revised form 17.02.2015, accepted 24.03.2015

The problem of linear baroclinic seiches in rectangular basin is considered. It is supposed that density is stratified into three layers. Internal waves are not taken into account. It is shown that one-dimensional model allows one to determine the positions of thermocline and halocline. The model also allows one to determine the values of temperature and salinity in the surface and bottom layers with satisfactory accuracy. Fluctuations of temperature and salinity in pycnocline are estimated by calculating parameters of baroclinic seiches. The results of calculations and measurements in Lake Shira are compared.

Keywords: internal seiche, three-layer stratification, vertical distribution of temperature and salinity of water, Lake Shira.

\section{Introduction}

In closed reservoirs circulation flows caused by wind and horizontal water density gradient are formed. A temperature regime of a reservoir is determined by the flow of heat through the water surface and by heat exchange with the surrounding water masses, that is, it is carried out by advection and turbulent diffusion. The one-dimensional mathematical model to describe vertical distribution of water temperature and salinity was proposed $[1,2]$. In the one-dimensional approximation the vertical distributions of temperature and salinity are determined by the vertical exchange of heat and mass. The vertical turbulent exchange coefficient is defined by the Prandtl-Obukhov formula and by the Ekman approximation for wind currents.

Density stratification of a lake is formed due to heating of the upper water layer and stratification in halocline. In stratified reservoirs internal waves are formed. Internal waves are either

\footnotetext{
*sv@icm.krasn.ru

†ibp@ibp.ru

†tolomeev@ibp.ru

(c) Siberian Federal University. All rights reserved
} 
travelling waves or standing waves. Standing internal wave (or baroclinic (internal) seiche) is a result of the changes in pressure field over time, the influence of non-stationary wind stress on the water surface. There is an extensive literature on mathematical modeling of internal seiche in stratified reservoirs (see, eg, [3-7]). The results of field measurements of flow velocities and water temperature in Lake Shira can be found in $[8,9]$. Oscillations of water temperature and vertical component of flow velocity was detected. This is the characteristic feature of internal waves in a stratified reservoir.

To evaluate the effect of internal waves on dynamics of the vertical structure of a stratified reservoir simple three-layer model of baroclinic seiches is used (Fig. 1). In stratified reservoirs one can distinguish upper mixed layer called epilimnion $\left(-d_{1} \leqslant z \leqslant 0\right)$, lower layer called hypolimnion $\left(d_{2} \leqslant z \leqslant d_{1}+d_{3}\right)$ and there is metalimnion (pycnocline) between them $\left(0 \leqslant z \leqslant d_{2}\right)$. In the metalimnion fluctuations of temperature and water salinity are observed. These fluctuations can have a significant impact on dynamics of the vertical distribution of oxygen and nutrients.

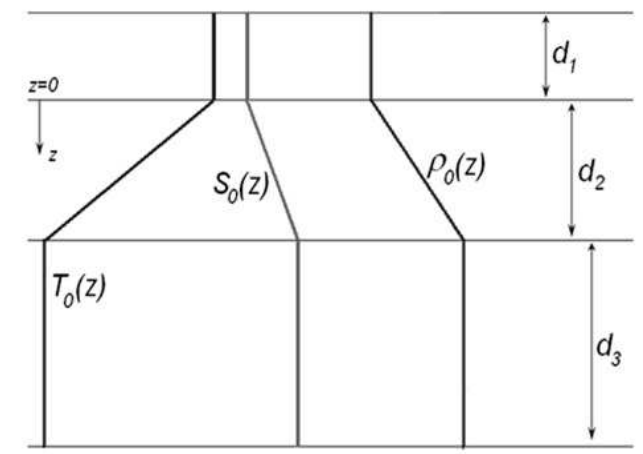

Fig. 1. Three-layered structure of the reservoir

In this paper we consider the use of the one-dimensional vertical model for parametrization of a vertical hydrophysical structure in the deep area of the stratified lake. The model takes into account the internal seiche. Examples of calculations of the vertical distribution for temperature and salinity in Lake Shira are given. Results are compared with the data of field measurements.

\section{A one-dimensional (in the vertical direction) model of a salt lake}

The object of research is Lake Shira. Lake Shira $\left(90^{0} 11^{\prime} \mathrm{E}, 54^{0} 30^{\prime} \mathrm{N}\right)$ is located in the northern part of the Republic of Khakassia (Southern Siberia, Russian Federation), $17 \mathrm{~km}$ away from the town of Shira. This is a large saline meromictic lake. The area of the lake is $39.5 \mathrm{~km} 2$ and its maximum depth is about $24 \mathrm{~m}$. The lake is closed, with the water inflow provided by the Son River and by atmospheric, underground and anthropogenic runoffs. At a depth of 12-13 $\mathrm{m}$ and below, there is a stable anaerobic zone in the lake with hydrogen sulfide concentration in the near-bottom layers varying from 15 to $20 \mathrm{mg} / \mathrm{L}$. In summer, when density stratification is well defined, mineral salt concentration in water in the epilimnion is about $10 \mathrm{mg} / \mathrm{L}$ and in the hypolimnion is about $14 \mathrm{mg} / \mathrm{L}$. All measurements were performed at several vertical lines in the deepest part of the lake. Vertical profiles of temperature and conductivity were measured with the use of Data-Sonde 4a submersible multi-channel probe (Hydrolab, USA) from 1 June to 19 Jule 2011 and from 13 to 30 June 2013. Meteorological data were taken from the Internet site "Weather records" (http://rp5.ru/Weather_archive_in_Shira). 
1.1. Vertical distribution of temperature and salinity in the deep region in various seasons can be defined by the one-dimensional model [1,2]. Formation of temperature regime in non-flowing stratified reservoirs (in the absence of ice) is due to wind currents and heat exchange with the atmosphere. The problem for the temperature distribution is formulated as follows [1,2]:

$$
\frac{\partial T}{\partial t}=\frac{\partial}{\partial z}\left(K_{T} \frac{\partial T}{\partial z}\right)+\alpha \beta \frac{F_{I} e^{-\beta z}}{c_{p} \rho_{0}} .
$$

The boundary conditions have the form

$$
K_{T} \frac{\partial T}{\partial z}=-\frac{F_{n}}{c_{p} \rho_{0}} \quad \text { for } z=0, \quad K_{T} \frac{\partial T}{\partial z}=\frac{F_{H}}{c_{p} \rho_{0}} \quad \text { for } z=H,
$$

here $T$ is the water temperature, $K_{z}(z)$ is the coefficient of vertical turbulent mixing, $F_{H}$ is the heat exchange with the bottom, $F_{n}$ is the total heat flow through the free surface, $F_{I}$ is the incoming short-wave solar radiation, $\beta$ is the radiation absorption coefficient, $\alpha$ is the parameter that defines the portion of radiation penetrating into deep-water layers $(0 \leqslant \alpha \leqslant 1), c_{p}$ is the specific heat capacity of water, $\rho_{0}$ is the typical water density, $H$ is the depth of a lake, $z$ is the vertical coordinate.

The problem for the vertical distribution of salinity is similarly formulated:

$$
\begin{gathered}
\frac{\partial S}{\partial t}=\frac{\partial}{\partial z}\left(K_{S} \frac{\partial S}{\partial z}\right), \\
K_{S} \frac{\partial S}{\partial z}=-F_{S} \quad \text { for } z=0, \quad K_{S} \frac{\partial S}{\partial z}=F_{S H} \quad \text { for } z=H .
\end{gathered}
$$

Here $S$ is the water salinity, $K_{S}(z)$ is the coefficient of vertical turbulent mixing for salinity, $F_{S H}$ is the mass exchange with the bottom, $F_{S}$ is the flow of salt across the free surface. It is also necessary to set the initial distributions of temperature and salinity:

$$
T(0, z)=T^{0}(z), \quad S(0, z)=S^{0}(z) .
$$

1.2. Parametrization of the coefficient of vertical turbulent exchange Turbulence considerably influences the heat and mass transfer. For parameterization of vertical turbulent exchange the formula obtained on the basis of the Prandtl-Obukhov formula and approximate Eckman solution for wind currents is used [1]:

$$
K_{z}=\left\{\begin{array}{ccc}
\left(0.05 h_{1}\right)^{2} \sqrt{\left(\frac{\tau}{\rho_{0} K_{0}}\right)^{2} e^{-2 \alpha z}-\frac{g}{\rho_{0}}\left(\frac{\partial \rho}{\partial z}\right)}+K_{\min } & \text { for } & B \geqslant 0, \\
K_{\min } & \text { for } \quad & B<0 .
\end{array}\right.
$$

Here $B=\left(\frac{\tau}{\rho_{0} K_{0}}\right)^{2} e^{-2 \alpha z}-\frac{g}{\rho_{0}}\left(\frac{\partial \rho}{\partial z}\right), \tau=\sqrt{\tau_{x}^{2}+\tau_{y}^{2}}$ is the wind stress, $K_{\min }=0.02 \mathrm{sm}^{2} / \mathrm{s}$ is the background value of the vertical turbulent exchange coefficient, $K_{0}=\frac{(0.05 \pi)^{2} \tau}{2 \rho_{0} f}, \alpha=\sqrt{\frac{f}{2 K_{0}}}$, $h_{1}=\pi \sqrt{\frac{K_{0}}{2 f}}, f$ is the Coriolis parameter.

The diffusion coefficients of heat and salt transfer in water are less than the coefficient of viscosity. In this paper we suppose

$$
K_{T}=K_{S}=\left\{\begin{array}{l}
K_{z} \quad \text { for } z \leqslant h \\
K_{\min } / 10 \text { for }\left(z>h \text { and } K_{z}=K_{\min }\right) .
\end{array}\right.
$$


We also suppose that the intensity of the vertical turbulent exchange is defined by the velocity gradient and stratification.

1.3. Parameterization of density. For fresh water density depends only on temperature. The Boussinesq approximation for seawater is taken as state equation for salt water:

$$
\rho=\rho_{0}\left(\varepsilon_{1}+\varepsilon_{2} \frac{T}{T_{0}}+\varepsilon_{3} \frac{S}{S_{0}}\right),
$$

where $\rho_{0}=1.0254 \mathrm{~g} / \mathrm{sm}^{3}, \varepsilon_{1}=0,9753, \varepsilon_{2}=-0.00317, \varepsilon_{3}=0,02737, T_{0}=17.5^{\circ} \mathrm{C}, S_{0}=35 \%$.

1.4. Parametrization of the heat flows and wind stress. The heat flows are important parameters affecting the temperature conditions of the reservoir. The total heat flow through a free surface is defined by the relation:

$$
F_{n}=(1-\alpha) F_{I}-\left(F_{e f}+F_{c o n v}+F_{e v}\right),
$$

where $F_{I}$ is the incoming short wave solar radiation, $F_{e f}$ is the effective long-wave radiation, $F_{e v}$ is the evaporation heat, $F_{c o n v}$ is the convective heat exchange. The components of the heat flux are determined by known formulas [10].

The wind shear stress is defined by the Saimons formula

$$
\tau=1.5 \cdot 10^{-2} \cdot W^{2},
$$

here $W$ is wind speed $(\mathrm{m} / \mathrm{s}), \tau$ is wind stress $\left(\mathrm{g} /\left(\mathrm{sm} \cdot \mathrm{s}^{2}\right)\right)$.

\section{Internal waves in a three-layer reservoir}

To evaluate the effect of internal waves on the vertical structure of stratified reservoir the following simplified formulation of the problem is considered. Stratified reservoir is schematized as three-layer fluid (Fig. 1). In the top water layer adjacent to a free surface $\left(-d_{1} \leqslant z \leqslant 0\right)$, the density of water is constant due to mixing, in the pycnocline $\left(0 \leqslant z \leqslant d_{2}\right)$ the density varies linearly with depth, in the bottom layer $\left(d_{2} \leqslant z \leqslant d_{1}+d_{3}\right)$ the density does not vary with depth, $\rho \approx$ const; $d_{1}, d_{2}, d_{3}$ are thicknesses of the respective layers, $d_{1}+d_{2}+d_{3}=H$ is the reservoir depth. The water density is supposed to be continuous on boundaries of the layers $z=0$ and $z=d_{2}$ (Fig. 1). $N=\sqrt{\frac{g}{\rho_{00}} \frac{d \rho_{0}}{d z}}$ is the Brunt-Vaisala frecuency, $\left(\rho_{0}(z)\right.$ is unperturbed density distribution, $\rho_{00}$ is the characteristic density and $g$ is the standard acceleration due to gravity). For this scheme $N_{1}=0, N_{2}=$ const, $N_{3}=0$.

Our study of wave processes in liquids is based on the linearized equations of hydrodynamics $[3,4]$. It was noted [3] that the Boussinesq approximation (gravity force depends only on water density) and the "solid cover" approximation (the vertical component of the water flow velocity is equal to zero on the free surface $z=-d_{1}$ ) can be used. Internal waves have substantially greater height than surface wave because the work needed to lift a water layer in air is greater than the work needed to lift a water layer in water. Therefore, the condition of the "solid cover" is quite acceptable $[3,11]$. The problem of oscillation of a three-layer fluid in a closed reservoir of rectangular shape with the flat bottom is considered: $0 \leqslant x \leqslant L, 0 \leqslant z \leqslant H, H=$ const is the reservoir depth. The Boussinesq approximation, approximation of hydrostatics and the "solid cover" approximation are used. Flows in vertical plane are considered. Linear equations of stratified fluid have the form [3]:

$$
\begin{array}{ll}
\frac{\partial u}{\partial t}=-\frac{1}{\rho_{00}} \frac{\partial p}{\partial x}, & \frac{\partial p}{\partial z}=g \rho \\
\frac{\partial u}{\partial x}+\frac{\partial w}{\partial z}=0, & \frac{\partial \rho}{\partial t}+w \frac{d \rho_{0}}{d z}=0 .
\end{array}
$$


Here $x$ and $z$ are rectangular coordinates, axis $z$ is directed downward, $t$ is time, $\bar{V}=(u, w)$ is the velocity vector of water flow, $p$ is pressure, $\rho$ is water density. Basic equation of internal wave with respect to vertical velocity $w$ follows from (8):

$$
\frac{\partial^{2}}{\partial t^{2}}\left(\frac{\partial^{2} w}{\partial z^{2}}\right)+N^{2} \frac{\partial^{2} w}{\partial z^{2}}=0
$$

Let us consider boundary conditions for the three-layer fluid (Fig.1). On the water surface (in the "solid cover" approximation) and at the bottom the vertical velocity is equal to zero

$$
w=0 \quad \text { for } z=-d_{1} ; \quad z=d_{2}+d_{3} .
$$

On the boundaries of layers kinematic (the linear approximation for vertical velocity) and dynamic (the total pressures on the both sides of the border are equal) boundary conditions are satisfied:

$$
\begin{aligned}
& w_{1}=w_{2} \quad \text { for } z=0, \quad w_{2}=w_{3} \quad \text { for } z=d_{2}, \\
& g\left(\rho_{1} \frac{\partial^{2} w_{1}}{\partial x^{2}}-\rho_{2} \frac{\partial^{2} w_{2}}{\partial x^{2}}\right)=\rho_{2} \frac{\partial^{3} w_{2}}{\partial t^{2} \partial z}-\rho_{1} \frac{\partial^{3} w_{1}}{\partial t^{2} \partial z} \quad \text { for } z=0 \\
& g\left(\rho_{2} \frac{\partial^{2} w_{1}}{\partial x^{2}}-\rho_{3} \frac{\partial^{2} w_{3}}{\partial x^{2}}\right)=\rho_{3} \frac{\partial^{3} w_{3}}{\partial t^{2} \partial z}-\rho_{2} \frac{\partial^{3} w_{2}}{\partial t^{2} \partial z} \quad \text { for } z=d_{2} .
\end{aligned}
$$

We seek a solution of equation (9) that satisfies boundary conditions (10), (11) in the form of a harmonic standing wave (baroclinic seiche):

$$
w(t, x, z)=\varphi(z) \cdot \cos k x \cdot \cos \omega t,
$$

$\omega$ is the wave frequency, $\lambda=\frac{2 \pi}{k}$ is the wave length.

From (9) and (12) follows

$$
\frac{d^{2} \varphi}{d z^{2}}+\frac{N^{2}}{c^{2}} \varphi=0, \quad c=\frac{\omega}{k} .
$$

From boundary conditions (10), (11) we obtain

$$
\begin{array}{ll}
\varphi_{1}\left(-d_{1}\right)=0, & \varphi_{3}\left(d_{2}+d_{3}\right)=0, \\
\varphi_{1}(0)=\varphi_{2}(0), & \varphi_{2}\left(d_{2}\right)=\varphi_{3}\left(d_{3}\right), \\
\varphi_{1}^{\prime}(0)=\varphi_{2}^{\prime}(0), & \varphi_{2}^{\prime}\left(d_{2}\right)=\varphi_{3}^{\prime}\left(d_{3}\right),
\end{array}
$$

where $\varphi_{i}^{\prime}=\frac{d \varphi_{i}}{d z}$

$$
\begin{aligned}
\text { Because } N_{1}= & 0, N_{2}=\sqrt{\frac{g \triangle \rho}{\rho_{00} d_{2}}}, N_{3}=0, \triangle \rho=\rho_{3}-\rho_{1}, \text { the solution of (13) is } \\
\varphi_{1}(z)=a_{1}+b_{1} z & \text { for }-d_{1} \leqslant z \leqslant 0, \\
\varphi_{2}(z)=a_{2} \cdot \sin \frac{N_{2}}{c} z+b_{2} \cdot \cos \frac{N_{2}}{c} z & \text { for }-0 \leqslant z \leqslant d_{2}, \\
\varphi_{3}(z)=a_{3}+b_{3} z & \text { for }-d_{2} \leqslant z \leqslant d_{2}+d_{3} .
\end{aligned}
$$

By virtue of (14), (15) we obtain uniform system of linear equations for constants $a_{i}, b_{i}(i=$ $1,2,3)$. The system has the nontrivial solution if the determinant of the system matrix is equal to zero. This gives us the dispersion relation for internal waves:

$$
\operatorname{tg} \frac{N_{2} d_{2}}{c}=\frac{\left(d_{1}+d_{3}\right) c N_{2}}{d_{1} d_{3} N_{2}^{2}-c^{2}}
$$


Solution of equation (16) is found iteratively with the use of the Newton method. Coefficients $a_{i}, b_{i}$ are calculated as follows

$$
\begin{aligned}
& b_{1}=\frac{a_{1}}{d_{1}}, \quad b_{2}=a_{1}, \quad a_{2}=\frac{c}{N_{2}} b_{1}, \\
& a_{3}=\frac{d_{2}+d_{3}}{d_{1}}\left(\frac{N_{2} d_{1}}{c} \sin \frac{N_{2} d_{2}}{c}-\cos \frac{N_{2} d_{2}}{c}\right) a_{1}, \quad b_{3}=-\frac{a-3}{d_{2}+d_{3}} .
\end{aligned}
$$

The horizontal velocity $u$ is found from equation $\frac{\partial u}{\partial x}+\frac{\partial w}{\partial z}=0$ and (12):

$$
u(t, x, z)=-\frac{1}{k} \varphi^{\prime}(z) \cdot \sin k x \cdot \cos \omega t
$$

It follows from boundary conditions $u=0$ for $x=0$ and $x=L$ that $k=\frac{n \pi}{L}$. If $n=1$ it is single-node seiche, for $n=2$ it is two-node seiche, etc.

Let $u_{10}$ be characteristic value of horizontal velocity in the top layer, thus $u_{10}=-\frac{1}{k} \varphi_{1}^{\prime}=$ $-\frac{b_{1}}{k}$. Therefore

$$
a_{1}=-k d_{1} u_{10}
$$

Characteristic velocity of water flow $u_{10}$ is defined by [11]

$$
u_{10}=k_{W} \cdot W
$$

here $W$ is the wind velocity $(\mathrm{m} / \mathrm{s}), k_{W}=1.5 \div 1.9$ is the wind coefficient, $u_{10}$ in centimeter per second.

\section{Algorithm to estimate the effect of internal waves on vertical structure of a stratified lake}

At the first stage the one-dimensional problem (in vertical direction) (1)-(7) is solved. Vertical distributions of temperature, salinity and density of water are determined. They depend on weather data. At the second stage the calculated vertical distributions of temperature and salinity for specific day are schematized by three-layer liquid (Fig. 1):

$$
T=T_{0}(z), \quad S=S_{0}(z) \quad \text { for } t=t_{0}
$$

After that the fluctuations in temperature and salinity during the day are determined by the solving the following equations:

$$
\frac{\partial T}{\partial t}+w \frac{\partial T}{\partial z}=0, \quad \frac{\partial S}{\partial t}+w \frac{\partial S}{\partial z}=0 .
$$

They satisfy initial conditions (19). The vertical velocity is defined by relation (12).

\section{Results}

Calculations of the vertical distribution of temperature, salinity and water density in Lake Shira by one-dimensional model (1)-(7) were performed. Fig. 2 illustrates the observed and calculated temperature profiles. One-dimensional model without internal waves allows us to determine the positions of thermocline, halocline and pycnocline. It also allows us to determine 


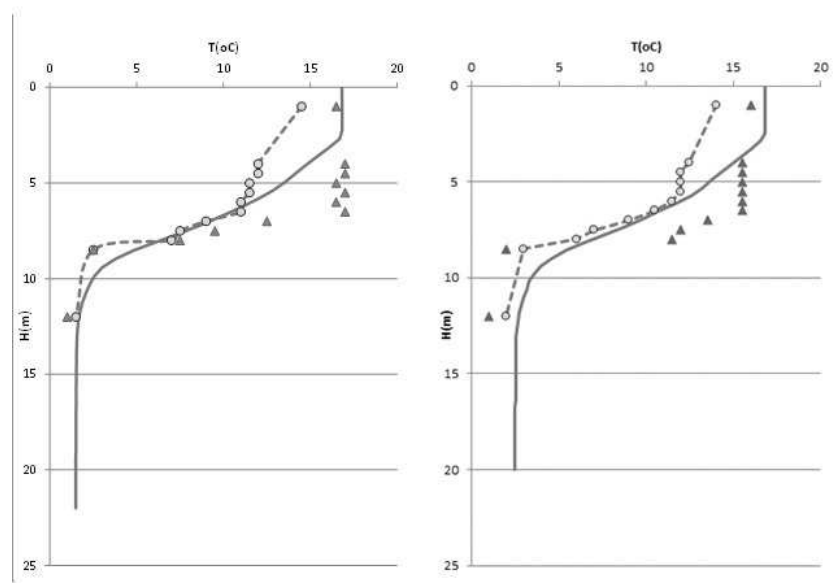

Fig. 2. Calculated (solid line) and observed (points) values of temperature for various verticals (24 June 2013). The initial distribution (dotted line) corresponds to the measured values of June 132013

the values of temperature and salinity in the surface and in the bottom layers with reasonable accuracy.

Fig. 3 shows the results of nature measurements for vertical water temperature distributions in deep part of Lake Shira for various verticals (identical markers correspond to the same vertical). We notice that the water temperature in the epilimnion and hypolimnion only slightly varies in the horizontal direction. Therefore we can apply the one-dimensional vertical model.
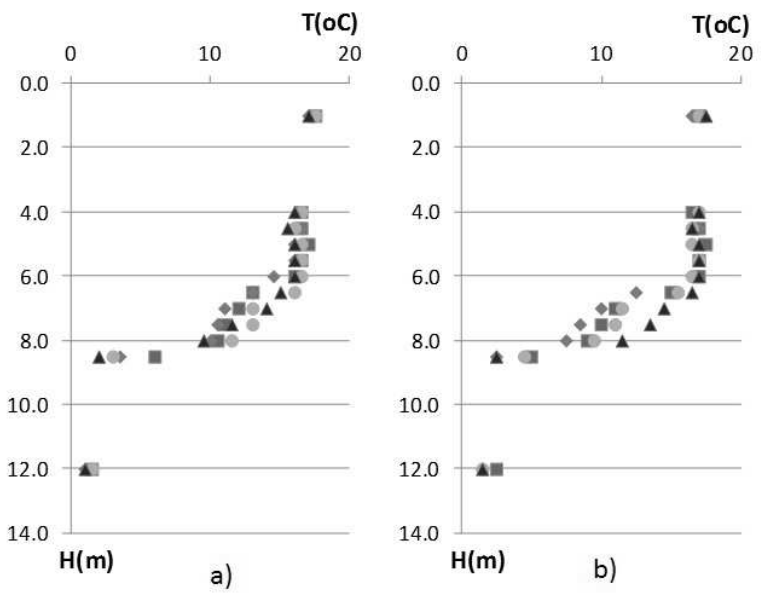

Fig. 3. Measured values of temperature in four verticals: a) June 272013 at $17 \mathrm{pm}$, b) June 30 2013 at $3 \mathrm{pm}$. Identical markers correspond to the same vertical

In real situation wind conditions are changed both in magnitude and in direction. Therefore a complex system of the internal waves appears. Noticeable fluctuations of the water temperature are observed in the pycnocline (Figs. 3, 4). Fluctuations of temperature and salinity are estimated by solving problems (20), (19) numerically with the use of the simplified model of the internal seiche (12), (15), (17), (18). Fig. 5 shows examples of calculations for the superposition of two modes of the single-node internal seiche. 


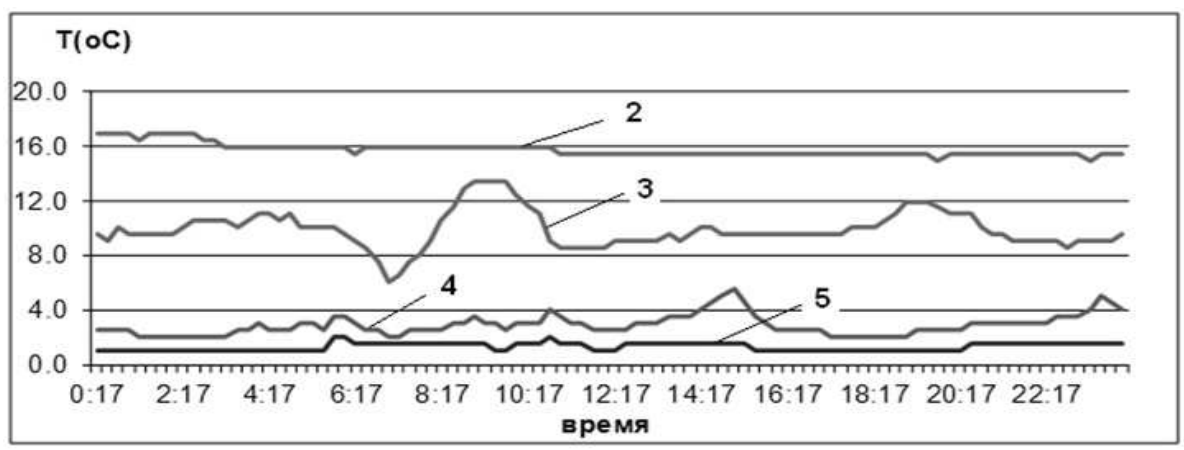

Fig. 4. Measured values of water temperature during one day at various depths $(2-5.5 \mathrm{~m}, 3-7.5 \mathrm{~m}$, $4-8.5 \mathrm{~m}, 5-12 \mathrm{~m})$

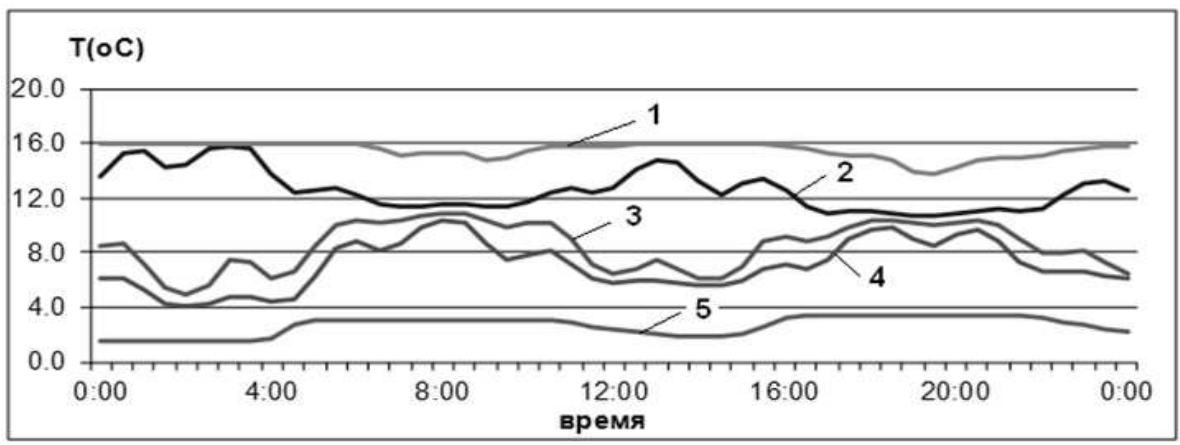

Fig. 5. Calculated values of water temperature at various depths $(1-3 \mathrm{~m}, 2-5.5 \mathrm{~m}, 3-7.5 \mathrm{~m}$, $4-8.5 \mathrm{~m}, 5-12 \mathrm{~m})$. The internal seiche is taken into account

A comparison of calculations and field measurements shows that the proposed algorithm allows us to determine the layer in which internal waves have a pronounced effect on oscillations of temperature and salinity in a stratified lake.

The dynamics of the vertical distribution of water temperature and salinity in stratified reservoirs can be predicted with the use of the one-dimensional vertical model, taking into account changes in meteorological parameters. Fluctuations of temperature and salinity in pycnocline can be estimated from the calculated vertical distributions of temperature and salinity by using the simplified one-dimensional model of internal waves.

The work was supported by the RFBR, grants (13-05-00853, 14-01-00296).

\section{References}

[1] V.M.Belolipetskii, S.N.Genova, Numerical modelling of an annual dynamics of the vertical structure of a salty lake, Comput Technol., 9(2008), no. 4, 34-43 (in Russian).

[2] S.N.Genova, V.M.Belolipetskii, D.Y.Rogozin,A.G.Degermendzhi, A one-dimensional model of vertical stratification of Lake Shira focussed on winter conditions and ice cover, Aquatic Ecology, 44(2010), 571-584.

[3] L.M.Brekhovskikh, V.V.Goncharov, Introduction to Mechanics of Continua environments (in the annex to the wave theory), Nauka, Moscow, 1982 (in Russian). 
[4] J.S.Turner, Buoyancy Effects in Fluids, Cambridge, University Press, 1973.

[5] S.F.Dotsenko, N.A.Miklashevskaya, Baroclinic seiches in rotating basins of variable depth in the case of two-layer density stratification, Physical Oceanography, 20(2010), no. 3, 157-169.

[6] I.V.Sturova, Internal Seiches in a Basin Filled with a Continuously Stratified Fluid, Fluid Dynamics, 49(2014), no. 6, 761-769.

[7] Waves and oscilations in the ocean and in lakes, In continuum mechanics in environmental science and geophysics edited by K. Hutter, Springer-Verlag, Berlin, New York, 1993.

[8] L.A.Kompaniets, T.V.Yakubaylik, O.S.Volodko, Analisys of the characterictics of the Shira Lake on the basis of field observations Vestnik Buryat Gos. Uviversitet. Matematika, informatika, (2012), no. 9, 167-176 (in Russian).

[9] V.I.Baranov, N.N.Golenko, L.A.Kompaniets, V.T.Paka, T.V.Yakubaylik, Spatial and temporal variability of the main characteristics of Lake Shira in the season of observations 20112012, Vestnik Buryat Gos. Uviversitet. Matematika, informatika, (2013), no. 9, 148-156 (in Russian).

[10] V.M.Belolipetskii, S.N.Genova, V.B.Tugovikov, Y.I.Shokin, Numerical modelling of problems of hydro-icethermics of currents, SB RAS, Novosibirsk, 1994 (in Russian).

[11] A.S.Sudolsky, Dynamic events in water bodies, Gidrometeoizdat, Leningrad, 1991 (in Russian).

\section{Бароклинные сейши в случае трехслойной плотностной стратификации в бассейнах прямоугольной формы}

Рассматривается задача о линейных бароклинных сейшах в бассейнах прямоугольной формы. Плотностная стратификация предполагается трехслойной. Показано, что одномерная модель без учета внутренних волн позволяет с удовлетворительной точностью определить положения термоклина и халоклина, а такюе значения температуры и солености воды в поверхностном и придонном слоях. Колебания температуры и солености воды в пикноклине ощениваются по рассчитанным параметрам бароклинных сейш. Результаты расчетов сопоставляются с данными измерений на озере Шира.

Ключевые слова: дифференциальные уравнения, задача Коши, расщепление, устойчивость, сходимость. 